Structure and chemical bonding 



\title{
Effect of acetate on ferrihydrite crystallization
}

\author{
Maria do Carmo Rangel Varela \\ Instituto de Química, Universidade Federal da Bahia, 40210 Salvador, Ba., Brazil \\ Milton Francisco de Jesus Filho ${ }^{1}$ \\ Departamento de Química, Universidade Federal de Minas Gerais, \\ 31270 Belo Horizonte, $M G$, Brazil \\ and \\ Fernando Galembeck \\ Instituto de Química, Universidade Estadual de Campinas, CP 6154, \\ 13081 Campinas, SP, Brazil
}

\begin{abstract}
Mössbauer spectroscopy was used to follow the aging of ferrihydrite with different amounts of acetate, to achieve more crystalline products. Mössbauer spectra of fresh samples did not show any magnetic components. After two years aging, the solids presented crystalline fractions. Hematite formation was inhibited as acetate content increased in solids. For an acetate/iron molar ratio equal to 0.63 goethite was formed instead of hematite. X-ray diffraction confirmed these results. This work shows that synthetic samples can be used for elucidating the "anti-hematitic" effect of organic matter already detected in soils.
\end{abstract}

\section{Introduction}

Ferrihydrite is a poorly crystalline hydrated ferric oxyhydroxide usually found in soils and weathered rocks. As a synthetic product, it is useful to prepare finely divided iron oxides for magnetic recording, pigments, catalysts, etc.

In soils, ferrihydrite with time transforms to more crystalline phases such as goethite, lepidocrocite and hematite in the weathering environment [1]. Goethite and hematite are by far the most common iron oxides occurring in soils and sediments [2]. Environmental conditions play a decisive role in determining which of the two forms are produced [3] probably because of their influence on the kinetics of the alternative reactions [2].

1 To whom correspondence should be addressed. 
A lot of laboratory studies have been carried out to investigate the conditions of iron oxide crystallization from ferrihydrite. The influence of $\mathrm{pH}$ [4] as well as the effect of relative humidity [5], silica content [6] and organic ions $[2,3,7]$ have been examined.

It has been demonstrated that some organic compounds retard or inhibit the transformation of ferrihydrite to more crystalline products in soils [8] and in the laboratory preparations [5]. Citrate, tartrate, malate and phosphate have a strong effect in inhibiting the crystallization whereas formiate, acetate, oxalate and malonate do not [3]. Earlier works [3,7] have shown that anions of organic acids influence both the rate of crystallization and the nature of crystalline products. Organic acids, in particular the hydroxy-carboxylic acids, can (i) retard crystallization of ferrihydrite to hematite, (ii) prevent goethite formation and (iii) in some cases, enhance hematite formation. The effect of the various organic acids depends on their nature and concentration as well as on the $\mathrm{pH}$ of the system [7].

Most of these investigations so far have been carried out in aqueous media on natural or synthetic samples. However, on dealing with model systems relevant for tropical soils, an important alternative is to consider the effect of organic matter on ferrihydrite crystallization keeping the samples in the powder form.

The aim of the present work is to follow the transformation of ferrihydrite powder with different amounts of acetate to more crystalline products. This study was carried out by preparing iron(III) hydroxide as hydrolysis product of aqueous ferric salt solution and then washing the gels produced with ammonium acetate solutions. During this washing acetate is adsorbed on the gels changing them to iron(III) hydroxoacetate (IHA), a poorly crystalline hydrated ferric oxyhydroxide, like ferrihydrite. The fresh samples were characterized by elemental analysis, infrared spectroscopy, X-ray diffraction, Mössbauer spectroscopy and electron diffraction. The aging of the samples was followed by Mössbauer spectroscopy and $\mathrm{X}$-ray diffraction on solids kept in closed vials at room temperature.

\section{Experimental}

All chemicals are analytical grade.

Iron(III) hydroxide was precipitated from $250 \mathrm{ml}$ of $1 \mathrm{~N}$ iron nitrate solution by the addition of $125 \mathrm{ml}$ of $25 \%$ ammonium hydroxide solution. The gel produced was rinsed six times with $600 \mathrm{ml}$ of ammonium acetate solution and then dried at $120^{\circ} \mathrm{C}$. Solids with different amounts of acetate were obtained by rinsing the gel with ammonium acetate solution of the following concentrations: $0.5,2,5$ and $20 \%$ $(m / v)$.

Iron contents were determined by titration with standard potassium bichromate solution [10]. Carbon elemental analysis was performed in a LECO 761-100 instrument.

Infrared spectra of the samples in the range of $200-4000 \mathrm{~cm}^{-1}$ were recorded in 
a model 1430 Perkin-Elmer spectrometer using CsI discs. X-ray analysis was done using a Phillips PW 1130 and a Rigaku instrument employing $\mathrm{Co} \mathrm{K} \alpha$ or $\mathrm{Cu} \mathrm{K \alpha}$.

A model Zeiss EM 902 microscope was used for electron diffraction studies.

Mössbauer spectra were obtained using a constant acceleration spectrometer with a triangular reference signal and a source of ${ }^{57} \mathrm{Co} \mathrm{diffused} \mathrm{in} \mathrm{rhodium.}$

\section{Results}

Iron and carbon contents of the solids produced vary with acetate concentration in the rinsing solution. The acetate/iron ratios are in the 0.04 to $0.63 \mathrm{range}$, as given in table 1.

The presence of acetate groups in the solids was detected by absorption bands at $1600-1400 \mathrm{~cm}^{-1}[9]$ in the infrared spectra.

Diffractograms of fresh samples do not show any diffraction lines, which is characteristic of materials possessing a poorly organized crystal structure and small particles.

After two years, the A sample (acetate/iron $=0.04$ ) shows the most important diffraction lines of hematite $(d=2.52,2.70$ and $3.69 \AA)$. For the D sample (acetate/iron $=0.63$ ) there is a weak signal corresponding to the $d=4.21 \AA$ line of goethite. For the other samples the lines of the two iron oxides mentioned above are not clear (fig. 1).

Electron diffraction of fresh samples confirmed the amorphous character of the fresh solids.

Mössbauer spectra at $85 \mathrm{~K}$ of fresh samples consist of only a sharp well-defined doublet. In fig. 2 is shown the spectrum of the sample having the lower acetate content (acetate/iron $=0.04$ ) and for the other samples the spectral shape is the same. The values of the quadrupole splitting $(\Delta)$ and isomer shift relative to iron metal $(\delta)$ are respectively, $\Delta=0.70 \pm 0.02 \mathrm{~mm} / \mathrm{s}$ and $\delta=0.47 \pm 0.02 \mathrm{~mm} / \mathrm{s}$.

Mössbauer spectra at room temperature of the two-years aged samples (fig. 2) show a doublet with broad lines $(\Gamma=0.45 \mathrm{~mm} / \mathrm{s})$ with $\Delta=0.68 \pm 0.02$ and a $\delta=0.34 \pm 0.02 \mathrm{~mm} / \mathrm{s}$ (table 2 ). The sample with acetate $/ \mathrm{Fe}=0.04$ shows in addition a sextet with broad lines $(\Gamma=0.77 \mathrm{~mm} / \mathrm{s})$ with an internal magnetic field of $494 \mathrm{kOe}$ and $\Delta=-0.24 \mathrm{~mm} / \mathrm{s}$. The spectral area did not change from 295 to $85 \mathrm{~K}$.

Table 1

Acetate/iron molar ratios in IHA samples and concentrations of ammonium acetate solution used for rinsing the gels.

\begin{tabular}{lll}
\hline Sample & Conc. $(\mathrm{g} / 100 \mathrm{ml})$ & Acetate $/$ iron ratio \\
\hline A & 0.5 & 0.04 \\
B & 2.0 & 0.25 \\
C & 5.0 & 0.50 \\
D & 20.0 & 0.63 \\
\hline
\end{tabular}




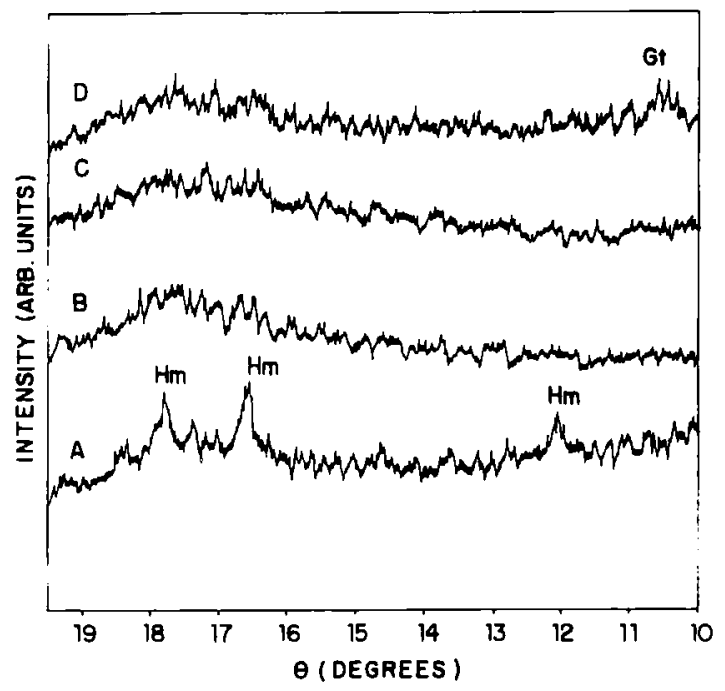

Fig. 1. Diffractograms of ferrihydrite with different amounts of acetate after two years of aging.

At this temperature, the solid with acetate/iron $=0.50$ presents almost the same spectrum as at room temperature. The spectra at $85 \mathrm{~K}$ of samples with acetate/Fe $=0.25$ and 0.63 show a sextet with low intensity and broad lines. The internal magnetic field are 521 and $494 \mathrm{kOe}$ respectively.

\section{Discussion and conclusions}

The Mössbauer parameters at $85 \mathrm{~K}$ of fresh samples are typical of iron hydroxides $[10,11]$. The broad lines show that the solids are formed by small amorphous particles. It was discussed by other authors [11] that it is difficult to distinguish the truly amorphous particles from the partially crystallized ones when the crystallites are too small to be detected by $\mathrm{X}$-ray diffraction. The electron diffraction of fresh samples confirmed their amorphous characteristics.

In the room temperature Mössbauer spectrum of aged sample with acetate/ iron $=0.04,19 \%$ of the spectral area correspond to hematite. Its low internal magnetic field and high linewidth $(\Gamma=0.77 \mathrm{~mm} / \mathrm{s})$ indicate the presence of particles of small size, probably smaller than $10 \mathrm{~nm}$. At $85 \mathrm{~K}$ there is a decrease of the linewidth of the sextet. As the sign of the quadrupole splitting did not change as the temperature decreased, the Morin transition was suppressed till that temperature [12]. These two last facts also confirm the small size of the particles for which there is a superparamagnetic relaxation. 


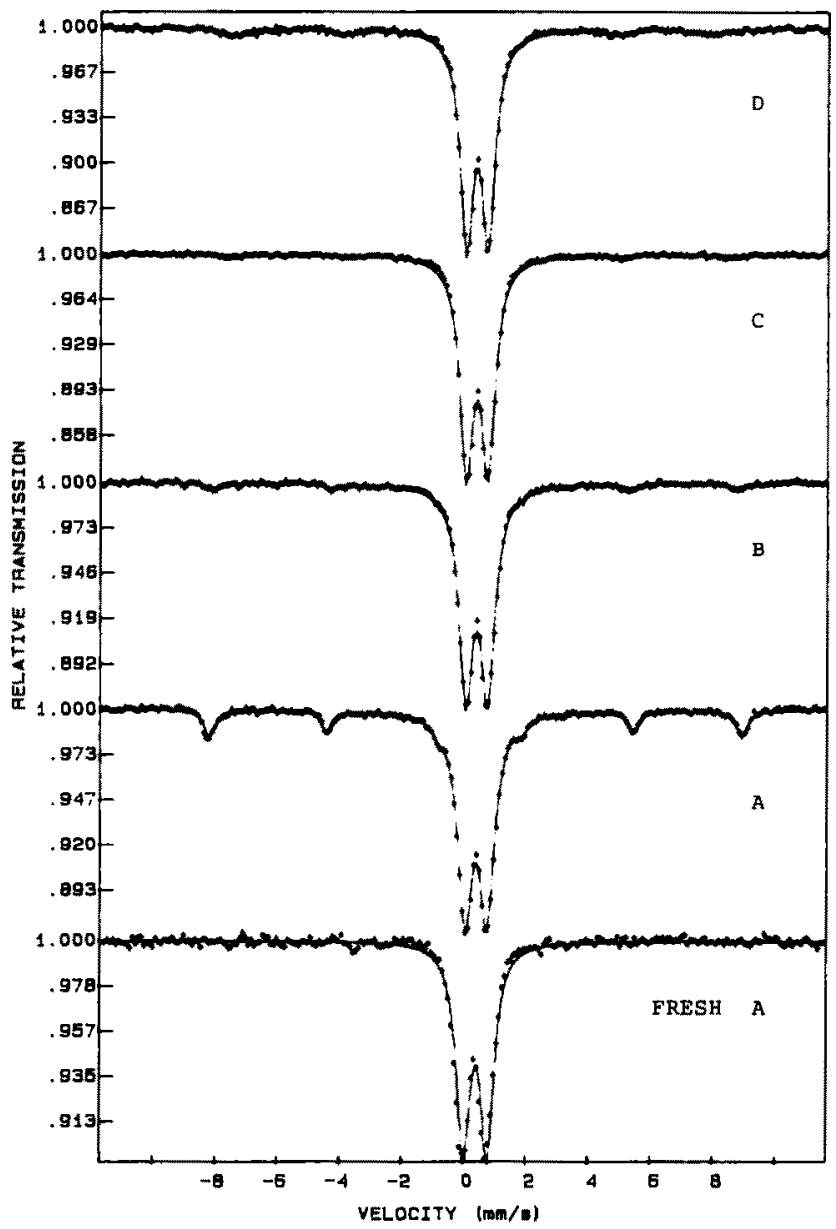

Fig. 2. Mössbauer spectra of IHA fresh and aged samples with different amounts of acetate. The spectra were recorded at $85 \mathrm{~K}$ temperature.

At $295 \mathrm{~K}$ the spectrum of aged solid with acetate $/$ iron $=0.25$ shows only a doublet. At $85 \mathrm{~K}, 7 \%$ of the spectral area are sextets whose parameters correspond to hematite. Thus the hematite particles in this sample present the superparamagnetic relaxation phenomenon due to their small sizes. It is also relevant to emphasize that the internal magnetic field of the B sample $(520 \mathrm{kOe})$ is lower than that of the $\mathrm{A}$ sample $(531 \mathrm{kOe})$. It shows that the hematite particles in the B sample are smaller than those in the A sample. So, from the spectral area and the internal magnetic field data we concluded that the crystallization rate was higher in the A sample than in the B sample. 
Table 2

Mössbauer parameters at 295 and $85 \mathrm{~K}$ of ferrihydrite with different amounts of acetate (Ac), after two years of aging.

\begin{tabular}{|c|c|c|c|c|c|c|c|}
\hline Sample & $\mathrm{Ac} / \mathrm{Fe}$ & $\begin{array}{l}T \\
(\mathrm{~K})\end{array}$ & $\begin{array}{l}\delta \\
(\mathrm{mm} / \mathrm{s})\end{array}$ & $\begin{array}{l}\Delta \\
(\mathrm{mm} / \mathrm{s})\end{array}$ & $\begin{array}{l}\Gamma \\
(\mathrm{mm} / \mathrm{s})\end{array}$ & $\begin{array}{l}H \\
\text { (kOe) }\end{array}$ & $\begin{array}{l}\text { Area } \\
(\%)\end{array}$ \\
\hline \multirow[t]{4}{*}{$\bar{A}$} & 0.04 & 295 & 0.34 & 0.68 & 0.48 & - & 81 \\
\hline & & & 0.40 & -0.24 & 0.77 & 494 & 19 \\
\hline & & 85 & 0.42 & 0.68 & 0.57 & - & 82 \\
\hline & & & 0.46 & -0.15 & 0.42 & 531 & 18 \\
\hline \multirow[t]{3}{*}{ B } & 0.25 & 295 & 0.34 & 0.66 & 0.43 & - & 100 \\
\hline & & 85 & 0.42 & 0.71 & 0.54 & - & 93 \\
\hline & & & 0.48 & -0.14 & 0.60 & 520 & 7 \\
\hline \multirow[t]{2}{*}{$\mathrm{C}$} & 0.50 & 295 & 0.33 & 0.70 & 0.45 & - & 100 \\
\hline & & 85 & 0.42 & 0.70 & 0.52 & - & 100 \\
\hline \multirow[t]{3}{*}{ D } & 0.63 & 295 & 0.30 & 0.66 & 0.45 & - & 100 \\
\hline & & 85 & 0.41 & 0.70 & 0.50 & - & 85 \\
\hline & & & 0.44 & -0.29 & 1.2 & 474 & 15 \\
\hline
\end{tabular}

The solid with acetate $/$ iron $=0.50$ showed no appreciable magnetically ordered fraction, that is, the intensity of the magnetic sextet is too weak to be fitted.

On the other hand, at $85 \mathrm{~K} 15 \%$ of the spectral area correspond to the magnetic fraction in the spectrum of the acetate/iron $=0.63$ sample in the aged sample. The low value of hyperfine magnetic field as well as the value of the $\Delta$ are consistent with the presence of goethite in accordance with the $\mathrm{X}$-ray diffraction results. The evaluation of this magnetic fraction has a great uncertainty in consequence of the low intensity of this sextet. No magnetic fraction was observed at room temperature, thus in this sample the phenomenon of superparamagnetism is also present.

These results show that acetate inhibits the hematite formation from ferrihydrite. At acetate/iron $=0.50$ and above no appreciable hematite is produced. For solids with acetate/iron $=0.63$, goethite is produced instead. So, roughly an acetate/iron ratio of 0.50 is enough to prevent hematite formation.

Schwertmann [3] had shown that acetate does not inhibit ferrihydrite crystallization. However, his experiments were carried out on suspensions of ferrihydrite in acidic solutions so that acetate effectiveness in suppressing crystallization depends on how strongly the acid adsorbs on ferrihydrite as well as on the medium $\mathrm{pH}$.

In our work, acetate is believed to be linked to iron atoms in IHA chains or adsorbed on iron hydroxide particles and so its role can be directly related to its concentration in solids.

The "anti-hematitic" effect of acetate described in this work has already been 
detected by Kämpf and Schwertmann [13] while studying the effect of organic matter in soils. However, it has not been satisfactorily explained nor has it been reproduced in the laboratory. The present work shows that synthetic samples can be used for emulating this important phenomenon.

Moreover, these results show that there is enough mobility within these dry powders, to allow crystallization to proceed at a detectable rate but very slowly. Earlier work [14] showed that on fresh samples the mobility is only detectable at temperatures up to $463 \mathrm{~K}$.

\section{Acknowledgement}

This work was supported by CNPq, FAPESP and FAPEMIG.

\section{References}

[1] R.A. Eggleton and R.W. Fitzpatrick, Clays Clay Miner. 36(1988) 111.

[2] W.R. Fischer and U. Schwertmann, Clays Clay Miner. 23 (1975) 33.

[3] U. Schwertmann, Geoderma 3(1969) 207.

[4] U. Schwertmann and E. Murad, Clays Clay Miner 31 (1983) 277.

[5] J. Torrent, R. Guzman and M.A. Parra, Clays Clay Miner. 30(1982) 337.

[6] R.K. Vempati and R.H. Loeppert, Clays Clay Miner. 37 (1989) 273.

[7] R.M. Cornell and U. Schwertmann, Clays Clay Miner. 27 (1979) 402.

[8] U. Schwertmann, Nature 212 (1966) 645.

[9] R.M. Silverstein, G.C. Bassler and T.C. Morrill, Identificaçāo Espectrométrica de Compostos Orgânicos (Guanabara Koogan, Rio de Janeiro, 1979) p. 88.

[10] E. Murad and U. Schwertmann, Amer. Mineral. 65 (1980) 1044.

[11] C.S.M. Partite, H. Rechenberg, P.P. Abreu Filho and F. Galembeck, Proc. Latin-Amer. Conf. on Applications of the Mössbauer Effect, Rio de Janeiro 1988, eds. E. Baggio-Saitovitch, E. Galvão da Silva and H.R. Rechenberg (World Scientific, Singapore, 1990) p. 327.

[12] G.M. da Costa, E. Galvāo da Silva and M.F. de Jesus Filho, Hyp. Int. 67 (1991) 501 .

[13] N. Kämpf and U. Schwertmann, Geoderma 29 (1982) 27.

[14] E.A. Pinheiro, P.P. Abreu Filho, F. Galembeck, E.C. Silva and H. Vargas, Langmuir 3 (1987) 445. 